\title{
ASO Visual Abstract: Adoption of Organ Preservation and Surgeon Variability for Patients with Rectal Cancer Does Not Correlate with Worse Survival
}

\author{
Jin K. Kim, MD ${ }^{1}$, Hannah Thompson, MD ${ }^{1}$, Rosa M. Jimenez-Rodriguez, MD ${ }^{1}$, Fan Wu, MS ${ }^{1}$, \\ Francisco Sanchez-Vega, PhD ${ }^{1,2}$, Garrett M. Nash, MD, MPH ${ }^{1}$, Jose G. Guillem, MD, MPH, MBS ${ }^{1}$, \\ Philip B. Paty, MD ${ }^{1}$, Iris H. Wei, MD ${ }^{1}$, Emmanouil P. Pappou, MD, PhD ${ }^{1}$, Maria Widmar, MD, MPH ${ }^{1}$, \\ Martin R. Weiser, MD ${ }^{1}$, J. Joshua Smith, MD, $\mathbf{P h D}^{1}$, and Julio Garcia-Aguilar, MD, $\mathbf{P h D}^{1}$ \\ ${ }^{1}$ Department of Surgery, Memorial Sloan Kettering Cancer Center, Colorectal Service, New York; ${ }^{2}$ Department of \\ Epidemiology and Biostatistics, Memorial Sloan Kettering Cancer Center, New York
}

Watch-and-wait is variably adopted by surgeons and the impact of this on outcomes is unknown. While neoadjuvant therapy type and organ preservation rates varied among surgeons in this study, there were no meaningful differences in disease-free survival (https://doi.org/10.1245/ s10434-021-10877-3).

\section{Adoption of Organ Preservation and Surgeon Variability for Patients With Rectal Cancer Does Not Correlate With Worse Survival}

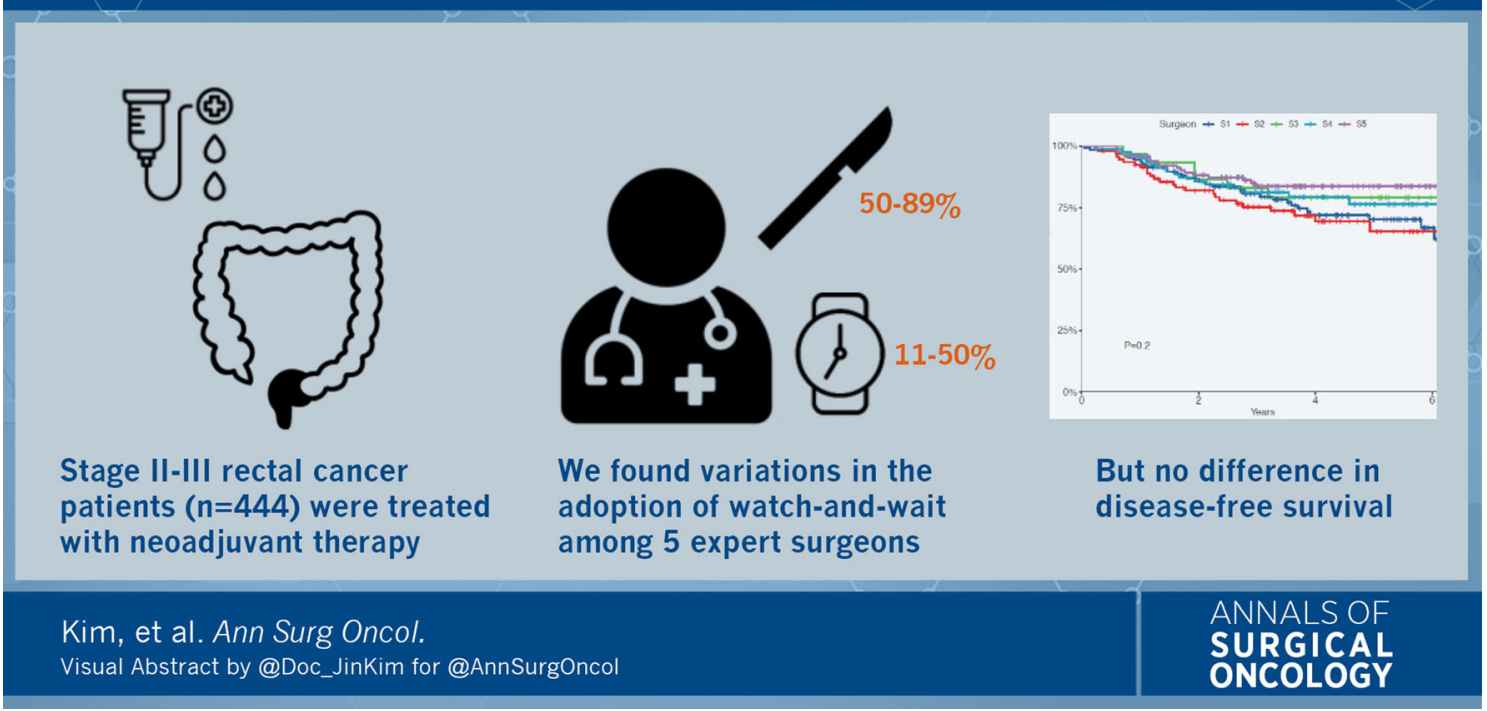

Jin K. Kim and Hannah Thompson these authors have contributed equally.

(C) Society of Surgical Oncology 2021

Published Online: 29 October 2021

J. Garcia-Aguilar, MD, $\mathrm{PhD}$

e-mail: garciaaj@mskcc.org
DISCLOSURES AND FUNDING SOURCES Dr. Kim was supported in part by NIH Grant T32CA009501. Dr. Smith has received travel support from Intuitive Surgical Inc. for fellow education (2015) and has served as a clinical advisor for Guardant Health, Inc (2019). Dr. Garcia-Aguilar has received honorarium for being a consultant with the following: Medtronics, Ethicon J\&J, Da Vinci Intuitive Surgical.

Publisher's Note Springer Nature remains neutral with regard to jurisdictional claims in published maps and institutional affiliations. 